\title{
PRIMEIRO ESTÁGIO JUVENIL DE AEGLA PRADO SCHMITT (CRUSTACEA, DECAPODA, ANOMURA, AEGLIDAE)
}

\author{
Georgina Bond-Buckup ${ }^{1}$ \\ Alessandra A.P. Bueno ${ }^{1}$ \\ Karina A. Keunecke ${ }^{1}$
}

\begin{abstract}
The First JUVEnIl Stage of AEgLA PRAdo Schmitt (CRUStacea, DeCAPODA, ANOMURA, AEglidaE). The first juvenil stage of Aegla prado Schimitt, 1942 is described and illustrated. The species $A$. prado showed a direct development, without the swimming free larval form. The most important appendages of the first juvenile stage were analysed: first and second antenna, mandible, first, second and third maxillipeds, first and fifth pereopods, telson and uropods. Setal formula for the first stage and setae characteristics are presented.

KEY WORDS. Crustacea, Decapoda, Aegla prado, juvenil, post embrionary development
\end{abstract}

Aeglidae compreende os únicos crustáceos anomura de água doce, destacando-se como elos importantes nas cadeias alimentares dos ambientes límnicos. São encontrados em arroios, riachos, rios de cavernas, rios de correnteza e lagoas da parte subtropical e temperada da América do Sul, desde a profundidade de $320 \mathrm{~m}$ em lagos chilenos, até cerca de $4.500 \mathrm{~m}$ de altitude no noroeste argentino (BONDBUCKUP \& BUCKUP 1994).

Apesar do expressivo número de espécies conhecidas atualmente, sessenta e uma, pouco se conhece sobre a biologia das mesmas. Os aspectos relacionados com o desenvolvimento e com a caracterização do indivíduo que eclode são ainda desconhecidos. FELDER et al. (1985) destacam que não se conhece larvas de Lomisidae, Pomatochelidae e Aeglidae. GORE (1985), apoiado em literatura específica, elaborou uma relação de crustáceos decápodos que possuem desenvolvimento direto destacando os camarões da infraordem Caridea, incluindo as famílias Alpheidae, Palaemonidae e Atyidae, alguns Stenopodidae, Thalassinidae, Paguridae, Galatheidae e Majidae, alguns caranguejos das superfamílias Dromioidea e Xantoidea e todos os caranguejos de água-doce, dos quais se conhece o desenvolvimento. Alguns autores preocuparam-se em estabelecer os padrões de desenvolvimento pós-larval de crustáceos decápodos e em utilizar uma terminologia apropriada para definir as formas larvais e pós-larvais; entre eles destacam-se WILLIAMSON (1969), FELDER et al. (1985) e GORE (1985). WILLIAMSON (1969), por exemplo, caracterizou o estágio juvenil como uma forma pós-larval usualmente pequena e sexualmente imatura exibindo características gerais de um adulto.

1) Laboratório de Crustáceos Superiores, Departamento de Zoologia, Universidade Federal do Rio Grande do Sul. Avenida Paulo Gama, prédio 12105, sala 323, 90040-060 Porto Alegre, Rio Grande do Sul, Brasil. 
Segundo NEGREIROS-Fransozo (1986), os caracteres mais frequentemente utilizados nos estudos morfológicos do desenvolvimento pós-embrionário de Brachyura são os tipos de antena, telso e escafognatito da maxila. Com o propósito de classificar as larvas de Anomura e Brachyura, VAN DOVER et al. (1982) apoiaram-se na análise da morfologia da segunda maxila. Os autores identificaram oito tipos diferentes de escafognatitos, usando a combinação de três características: a presença de um processo apical, o desenvolvimento de um lobo posterior e o grau de setação marginal.

RoDrigues \& HEBLING (1978), em estudos biológicos realizados com $A$. perobae Hebling \& Rodrigues, 1977, fizeram várias observações com os jovens récem eclodidos e constataram que estes ao eclodirem eram bastante parecidos com $\mathrm{o}$ adulto, medindo aproximadamente dois milímetros.

\section{MATERIAL E MÉTODOS}

Em agosto de 1993 foram coletadas fêmeas ovígeras do caranguejo de água doce Aegla prado nos canais do banhado da Estação Ecológica do Taim, Rio Grande, Rio Grande do Sul.

As fêmeas ovígeras foram mantidas em aquários, no laboratório, os quais foram monitorados semanalmente quanto aos aspectos físicos e químicos. Os indivíduos foram alimentados diariamente com peixe crú e ração a base de farinha de peixe, farinha de trigo, fubá, farinha de soja e água. Os animais eclodidos foram mantidos em recipientes individuais de cultivo com o objetivo de acompanhar a duração do primeiro estágio de desenvolvimento.

Alguns exemplares foram dissecados, as estruturas montadas em lâminas permanentes, desenhadas com auxílio da câmara lúcida, analisadas e comparadas. Posteriormente, outros exemplares foram preparados para fotografias em microscópio eletrônico de varredura JEOL-JSM 5.200, com ponto crítico CO2 Baltec CPD 030 e metalizador Baltec SCD 005, usando ouro e argônio por três minutos. Utilizou-se a técnica de preparo sugerida por SCOTTO (1980) para larvas de braquiúros. Na descrição das diversas estruturas analisadas, levou-se em consideração a variabilidade constatada em cinco animais dissecados. As estruturas consideradas importantes na identificação dos estágios pós-embrionários foram: antênulas, antenas, mandíbulas, maxílulas, maxilas, primeiro, segundo e terceiro maxilípodos, primeiro, segundo e quinto pereiópodos, telso e urópodos.

A caracterização das setas apoiou-se nos trabalhos de THOMAS (1970), WATLING (1989) e CALAZANS (1992). Na comparação das setas das estruturas mencionadas elaborou-se uma fórmula setal, apoiando-se nos estudos de BERSANO \& BOXSHALL (1994).

\section{RESULTADOS}

Aegla prado apresenta desenvolvimento direto, do tipo abreviado, sem formas larvais livre-natantes, caracterizado como juvenil (sensu GORE 1985). Assemelha-se, morfologicamente, à forma adulta. Os juvenis permanecem junto ao 
abdome da fêmea logo após a eclosão; têm hábito bentônico utilizando os pereiópodos e flexionando o abdome na locomoção.

Carapaça. Com 1,02 a 1,36mm de comprimento (CC); de 0,85 a $1,19 \mathrm{~mm}$ de largura (LC); carapaça sub-cilíndrica, sem elevação longitudinal, pouco expandida na região branquial, mais longa do que larga, superfície dorsal com sulco gástrico bem destacado; lobos hepáticos demarcados; seio extra-orbital presente, com pequeno espinho orbital; rostro triangular, largo na base, bem desenvolvido, alcançando a base da córnea, carenado; pereiópodos semelhantes aos dos adultos com espinhos reduzidos; abdome sem pleópodos. (Figs 1-2).

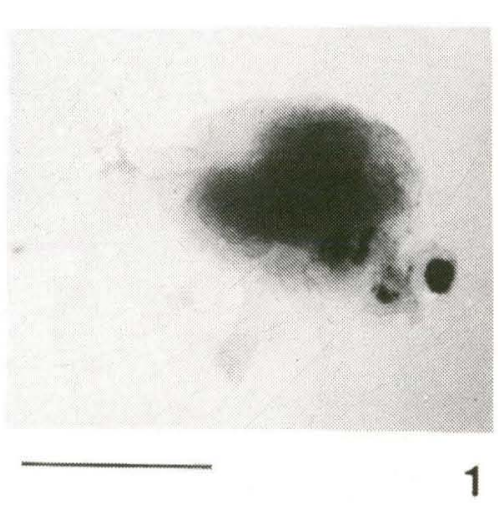

1

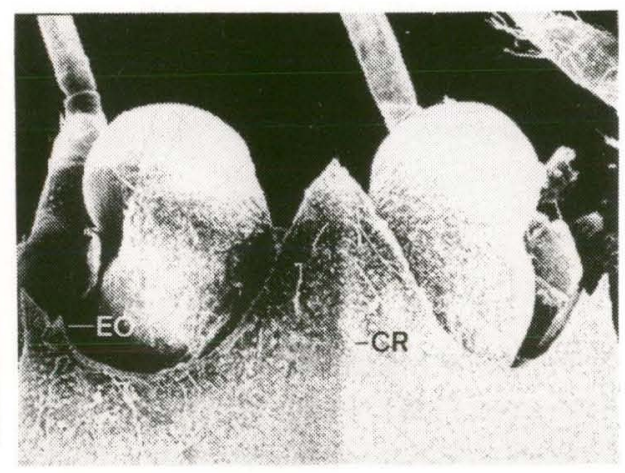

2

Figs 1-2. Aegla prado. (1) Primeiro estágio juvenil (escala = 1mm); (2) primeiro estágio juvenil [(CR) carena rostral, $(E O)$ espinho extra-orbital, escala $=100 \mu \mathrm{m})$.

A tabela I mostra a fórmula setal nas diferentes estruturas abaixo analisadas. Antênula (Fig. 3). Aspecto pediforme; artículo basal globoso com 11 setas simples e sete setulosas; artículo proximal com uma seta simples; artículo distal com três setas simples; flagelo dorsal tri-articulado com uma a duas setas simples, uma seta no artículo proximal e outra no distal, quatro estetascos, estruturas quimiorreceptoras, em posições apical e sub-apical (Fig. 15); flagelo ventral não articulado e com seis setas simples distais. 
Tabela I. Fórmula setal dos apêndices do primeiro estágio juvenil de Aegla prado. Legendas: setas - (I) simples, (II) setulosa, (III) denticulada, (IV) serrada, (V) paposa, (VI) estetascos, (VII) cuspidadas; segmentos das estruturas - (ab) artículo basal, (ad) artículo distal, (ap) artículo proximal, (bi) basipodito-isquiopodito, (c) carpopodito, (d) dactilopodito, (ed) endito distal, (en) endopodito, (ep) endito proximal, (ex) exopodito, (exe) exopodito externo, (exi) exopodito interno, (fl) flagelo, (fd) flagelo dorsal, (fv) flagelo ventral, (i) isquiopodito, (m) meropodito, $(p)$ propodito, $(p t)$ protopodito.

\begin{tabular}{|c|c|c|}
\hline Apêndices & Segmentos & Setas \\
\hline \multirow[t]{5}{*}{ Antenula } & $a b$ & $11 \mathrm{I} ; 7$ II \\
\hline & ad & 31 \\
\hline & ap & 11 \\
\hline & $\mathrm{fd}$ & $1-2 \mathrm{I} ; 4 \mathrm{VI}$ \\
\hline & fv & 61 \\
\hline \multirow[t]{4}{*}{ Antena } & bi & 11 \\
\hline & c & 41 \\
\hline & $\mathrm{fl}$ & 361 \\
\hline & $\mathrm{m}$ & 11 \\
\hline \multirow[t]{2}{*}{ Mandíbula } & ad & 2 I; 2 II;9 III \\
\hline & ap & $2 \mathrm{I} ; 1 \mathrm{II}$ \\
\hline \multirow[t]{3}{*}{ Maxilula } & ed & 5-6 II; 5-7 III; 10-11 VII \\
\hline & en & $2 \mathrm{II} ; 1 \mathrm{III}$ \\
\hline & ep & $1-2 \mathrm{I} ; 4-5 \mathrm{II} ; 6-10 \mathrm{III}$ \\
\hline \multirow[t]{3}{*}{ Maxila } & ed & $7 \mathrm{I} ; 14 \mathrm{III}$ \\
\hline & ep & $15 \mathrm{II} ; 11 \mathrm{II}$ \\
\hline & ex & $50-52$ II; 3 III \\
\hline \multirow[t]{4}{*}{ Primeiro Maxilípodo } & ed & $21 \mathrm{III} ; 7-9 \mathrm{~V}$ \\
\hline & en & $1-2 \|$ \\
\hline & ep & $2-3 \mathrm{I} ; 5 \mathrm{~V}$ \\
\hline & exe & $6-7$ II \\
\hline \multirow{8}{*}{ Segundo maxilipodo } & pt & $4-7 \mathrm{~V}$ \\
\hline & $\mathrm{i}$ & $4-5 \mathrm{~V}$ \\
\hline & $\mathrm{m}$ & $3-4$ III \\
\hline & c & $0-11$ \\
\hline & p & 7-8 III \\
\hline & d & $8 \mathrm{III} ; 2 \mathrm{IV}$ \\
\hline & ex & $5 \mathrm{l} ; 1 \mathrm{II}$ \\
\hline & $\mathrm{fl}$ & $1 \mathrm{I} ; 4 \mathrm{II}$ \\
\hline \multirow{8}{*}{ Terceiro maxilípodo } & pt & 111 \\
\hline & i & $7-81$ \\
\hline & $\mathrm{m}$ & $7 \mathrm{I} ; 31 \mathrm{III}$ \\
\hline & c & $10 \mathrm{I} ; 4 \mathrm{III}$ \\
\hline & $p$ & 2-3 I; 10-14 III; 4-6 IV \\
\hline & d & $2 \mathrm{I} ; 9 \mathrm{III} ; 8-10 \mathrm{IV}$ \\
\hline & ex & $1 \mathrm{I} ; 1 \mathrm{II}$ \\
\hline & $\mathrm{fl}$ & $1 \mathrm{I} ; 4 \mathrm{II}$ \\
\hline \multirow[t]{6}{*}{ Quinto pereiópodo } & $\mathrm{pt}$ & $3-41$ \\
\hline & i & $0-11$ \\
\hline & $\mathrm{m}$ & $0-11$ \\
\hline & c & 51 \\
\hline & $p$ & $15 \mathrm{I} ; 3 \mathrm{IV}$ \\
\hline & d & 1-4 I; 3 IV \\
\hline \multirow{4}{*}{$\begin{array}{l}\text { Telso } \\
\text { Urópodos }\end{array}$} & & $18 \mathrm{I} ; 17-20 \mathrm{II}$ \\
\hline & $a b$ & $1-21$ \\
\hline & ex & $3 \mathrm{I} ; 20-23$ II \\
\hline & en & $3 \mathrm{I} ; 18-19$ II \\
\hline
\end{tabular}



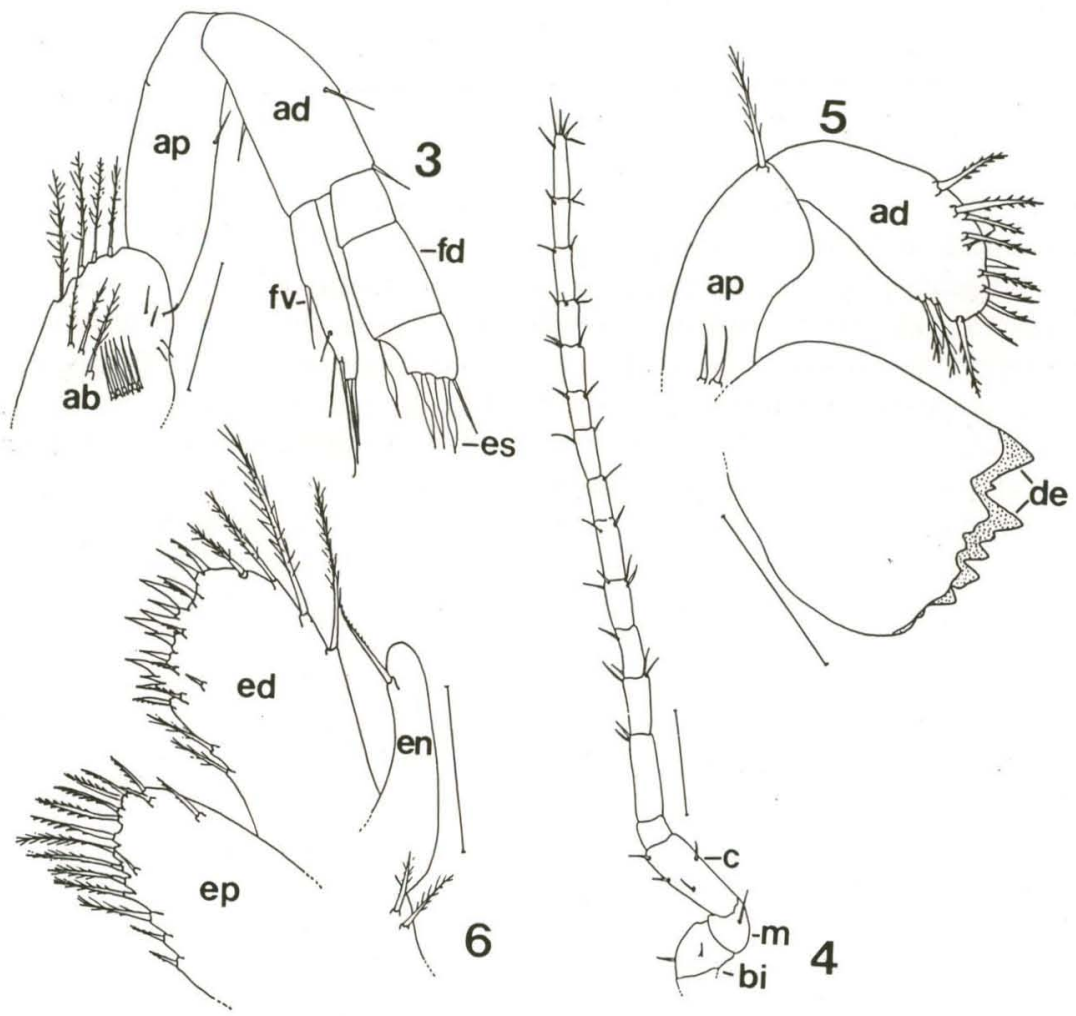

Figs 3-6. Aegla prado, primeiro estágio juvenil. (3) Antênula; (4) antena; (5) mandíbula; (6) maxilula. Legendas: (ab) artículo basal, (ad) artículo distal, (ap) artículo proximal, (bi) basipodito-isquiopodito, (c) carpopodito, (de) dentes, (ed) endito distal, (en) endopodito, (ep) endito proximal, (es) estetascos, (fd) flagelo dorsal, ( $\mathrm{fv}$ ) flagelo ventral, $(\mathrm{m})$ meropodito. Escalas: figuras $3,5-6=0,1 \mathrm{~mm}$; figura $4=0,2 \mathrm{~mm}$ ).

Antena (Fig. 4). Aspecto pediforme; 2,5 a 3,0 vezes mais longa do que a antênula; pedúnculo penta-articulado. Segundo e terceiro artículos, basipodito-isquiopodito, fusionados, de forma globosa, com uma seta simples proximal; quarto artículo, ou meropodito, com forma sub-triangular e uma seta simples distal; quinto artículo, ou carpopodito, sub-retangular, com quatro setas simples medianas e distais; flagelo bastante longo, multi-articulado, com 14 artículos subiguais com exceção do primeiro mais curto. Exceto o primeiro artículo, os demais possuem setas simples, 36, na margem distal.

Mandíbula (Fig. 5). Aspecto foliáceo e bem desenvolvida, semelhante a do adulto; processo incisivo bastante quitinizado, com cinco dentes pontiagudos, assimétricos e alguns dentículos entre esses; palpo mandibular robusto com dois artículos; artículo proximal com duas setas simples proximais e uma seta setulosa distal; artículo distal com duas setas simples, duas setulosas e nove denticuladas apicais e sub-apicais (Fig. 16). 
Maxílula (Fig. 6). Aspecto foliáceo, composta de endopodito e enditos. Área basal com duas setas setulosas proximais; endopodito alongado com uma seta denticulada distal; endito distal com cinco a seis setas setulosas, cinco a sete setas denticuladas e 10-11 setas cuspidadas dispostas na margem distal (Fig. 17); endito proximal com uma a duas setas simples, quatro a cinco setas setulosas e seis a 10 denticuladas ao longo da margem distal.

Maxila (Fig. 7). Apêndice birreme, com aspecto foliáceo, composto de exopodito, endopodito e enditos. Exopodito ou escafognatito, bastante desenvolvido, semelhante ao adulto, alongado, com 50 a 52 setas setulosas subiguais, mais longas, dispostas ao longo da borda e três setas simples; endopodito alongado e desarmado; endito distal bilobado; lobo distal mais proeminente com seis a sete setas simples e oito a 11 denticuladas; lobo proximal com uma seta simples e seis denticuladas; endito proximal bilobado, o primeiro lobo, distal, relativamente menor que o segundo; com quatro setas denticuladas e seis setulosas; o segundo lobo do endito proximal possui uma seta simples e oito setas setulosas, distribuindo-se distal e lateralmente, sete setas denticuladas apicais.

Primeiro maxilípodo (Fig. 8). Apêndice birreme com aspecto foliáceo. Exopodito com dois ramos alongados; ramo externo do exopodito com seis a sete setas setulosas na borda externa; ramo interno desprovido de setas; endopodito alongado, com uma a duas setas setulosas. Endito distal com 21 setas denticuladas dispostas na margem, e sete a nove paposas na porção mediana do artículo. Endito proximal menor em relação ao distal, com duas a três setas simples, cinco paposas sub-marginais.

Segundo maxilípodo (Fig. 9). Apêndice birreme; endopodito penta-articulado; protopodito com quatro a sete setas paposas na margem interna; isquiopodito sub-quadrático com quatro a cinco setas paposas; meropodito sub-retangular com três a quatro setas denticuladas próximas a borda interna; carpopodito sub-cilíndrico desarmado ou com apenas uma seta simples; propodito com sete a oito setas denticuladas, localizadas nas regiões mediana e distal; dactilopodito sub-cilíndrico com oito setas denticuladas na região mediana do ápice e duas setas serradas apicais; exopodito com cinco setas simples nas margens, e uma seta setulosa na margem interna; flagelo bi-articulado, com uma seta simples e quatro setas setulosas apicais.

Terceiro maxilípodo (Fig. 10). Apêndice birreme bem desenvolvido; endopodito penta-articulado; protopodito com 10 a 11 setas simples, localizadas nas regiões lateral e mediana; isquiopodito com sete a oito setas simples, situadas na região mediana do artículo; crista denteada, na porção interna da região lateral, formada por oito tubérculos esclerotizados; meropodito sub-retangular com sete setas simples e três denticuladas no lado interno; carpopodito sub-cilíndrico com 10 setas simples e quatro denticuladas na borda medio-distal; propodito com duas a quatro setas simples, 10 a 14 denticuladas e quatro a seis serradas na região medio-distal; dactilopodito sub-cilíndrico com ápice de contorno arredondado com duas setas simples, nove denticuladas e oito a 10 serradas localizadas nas porções mediana e marginal do artículo (Fig. 18); exopodito com uma seta simples e uma setulosa na margem interna; flagelo bi-articulado, com uma seta simples e quatro a cinco setas setulosas apicais. 


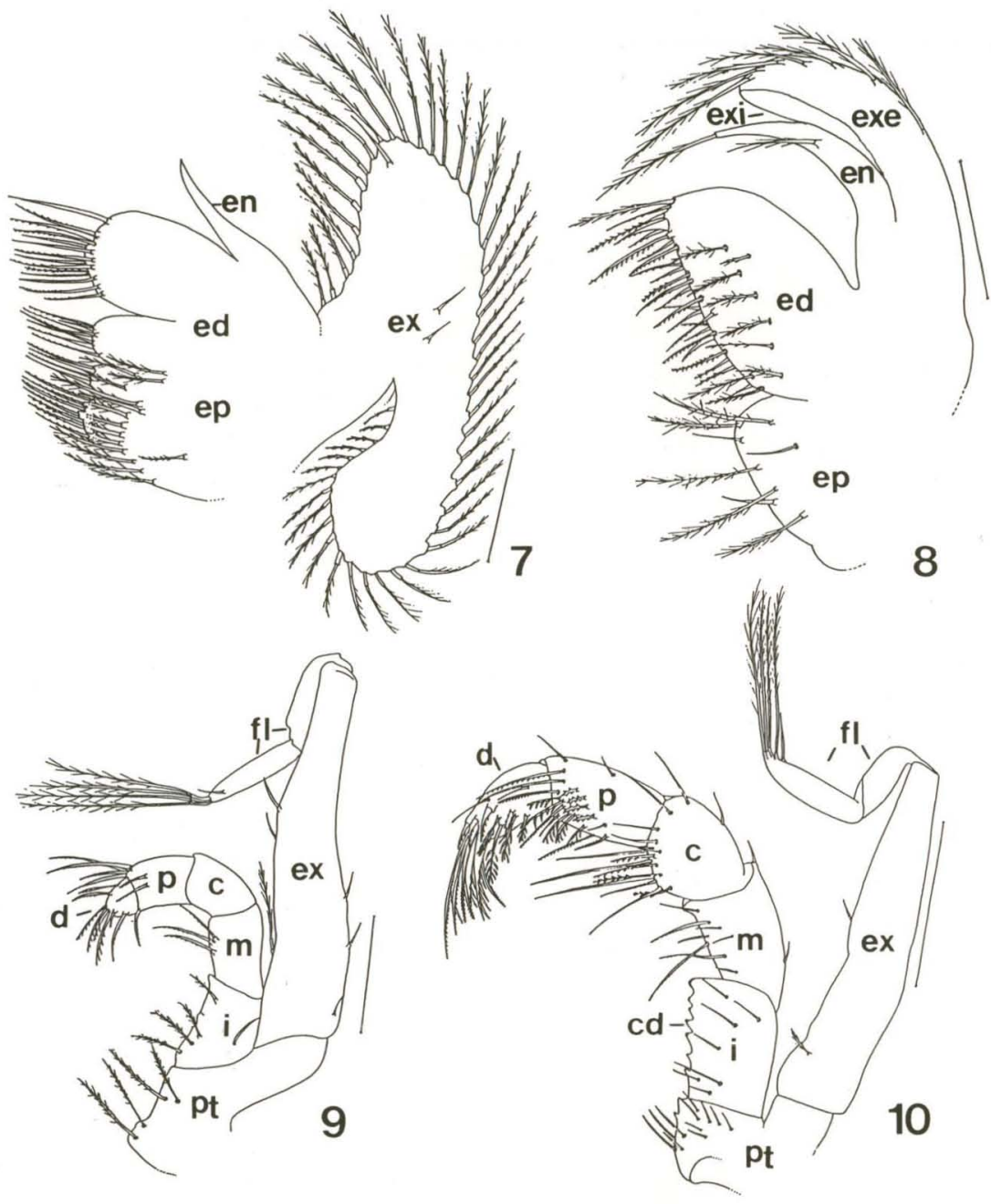

Figs 7-10. Aegla prado, primeiro estágio juvenil. (7) Maxila, (8) primeiro maxilípodo; (9) segundo maxilipodo; (10) terceiro maxilipodo. Legendas: (c) carpopodito, (cd) crista denteada, (d) dátilopodito, (ed) endito distal, (ep) endito proximal, (en) endopodito, (ex) exopodito, (exe) exopodito externo, (exi) exopodito interno, (fl) flagelo, (i) isquiopodito, ( $m$ ) meropodito, $(p)$ propodito, (pt) protopodito. Escalas: figuras $7-8=0,1 \mathrm{~mm}$, figuras $9-10=0,2 \mathrm{~mm}$.

Quelípodo (Fig. 11). Apêndice unirreme, de aspecto pediforme, mais robusto que os demais pereiópodos, com seis artículos. Basipodito-isquiopodito, não representados na figura, e meropodito sub-retangulares; carpopodito sub-triangular com um espinho robusto no bordo interno e um espinho destacado na porção ântero-distal; palma ou propodito, com modesto espinho próximo a inserção do dactilopodito; 
dedo fixo com nove dentículos na margem cortante e dois espinhos robustos apicais; dactilopodito ou dedo móvel, com 11 dentículos na margem cortante e um espinho robusto apical. Em todos os artículos observa-se várias setas simples dispostas aleatoriamente.

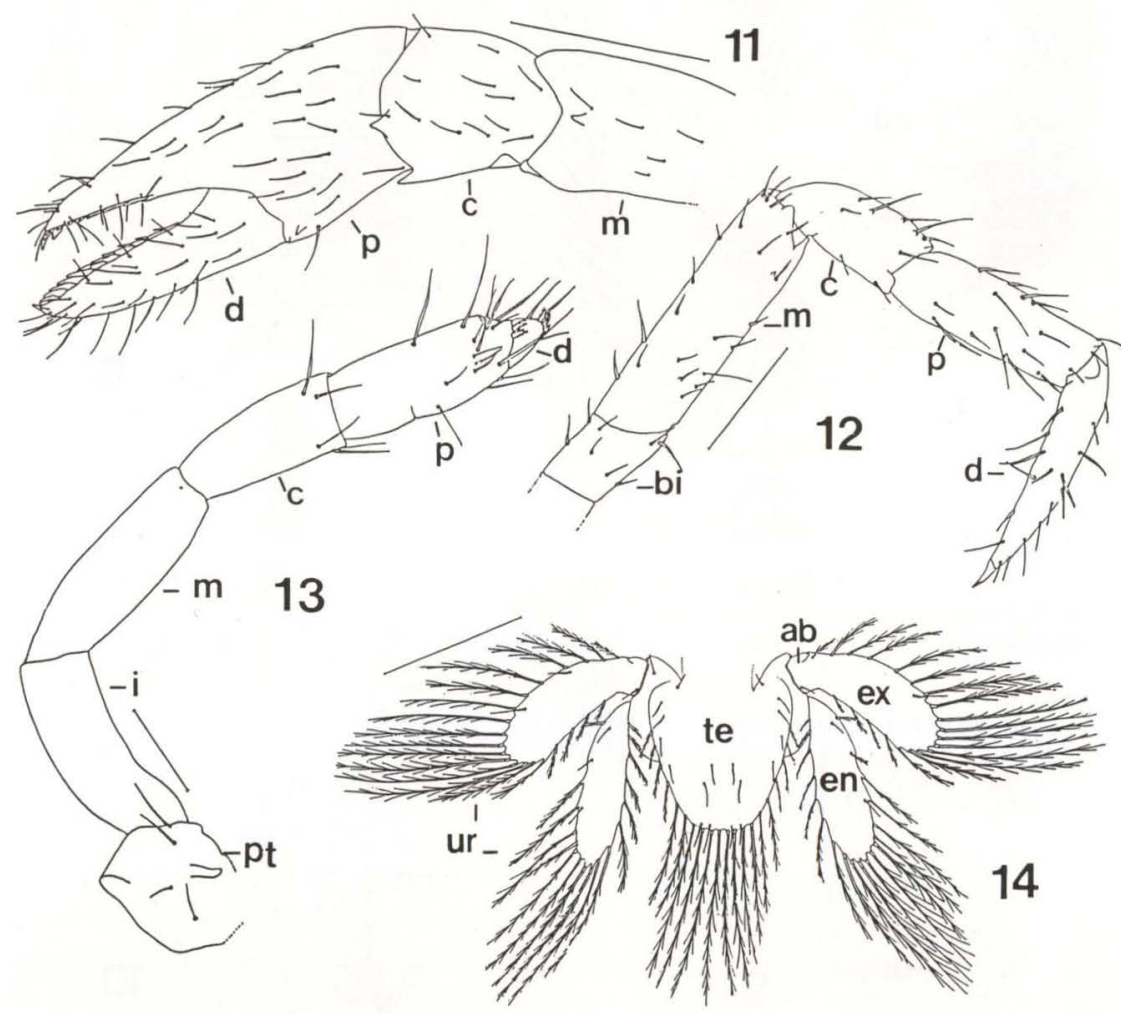

Figs 11-14. Aegla prado, primeiro estágio juvenil. (11) quelípodo; (12) segundo pereiópodo; (13) quinto pereiópodo; (14) telso e urópodos. Legendas: (ab) artículo basal, (bi) basipoditoisquiopodito, (c) carpopodito, (d) dactilopodito, (en)endopodito, (ex) exopodito, (i) isquiopodito, (m) meropodito, (p) propodito, (pt) protopodito, (te) telso, (ur) urópodos. Escalas: figuras 11-13 $=0,1 \mathrm{~mm}$; figura $14=0,2 \mathrm{~mm}$.

Segundo pereiópodo (Fig. 12). Apêndice unirreme, de aspecto pediforme; com seis artículos; coxa com aspecto globoso; basipodito-isquiodito com forma sub-retangular, porém, de menor comprimento em relação aos outros artículos; meropodito, carpopodito e propodito sub-retangulares; meropodito mais longo do que os demais artículos; dactilopodito sub-triangular com um robusto espinho apical; várias setas simples encontram-se espalhadas por todo apêndice. 
Terceiro e quarto pereiópodos de aspecto pediforme, semelhante ao segundo pereiópodo.

Quinto pereiópodo (Fig. 13). Unirreme, com aspecto pediforme, porém reduzido e atrofiado; com seis artículos: protopodito globoso, com três a quatro setas simples; isquiopodito e meropodito sub-retangulares, desarmados ou com uma seta simples; carpopodito sub-retangular com cinco setas simples distais; propodito com 15 setas simples medio-distais e três setas serradas, situadas no ápice do artículo; dactilopodito com uma a quatro setas simples e três setas serradas apicais; o dactilopodito, juntamente com o propodito formam uma pequena quela.

Telso (Fig. 14). Laminar, de forma sub-triangular, inteiro, sem sutura longitudinal, com 17 a 20 setas setulosas distribuidas ao longo da margem póstero-distal, as mais longas situadas na região apical; 18 setas simples marginais, sub-marginais e mediais.

Urópodos (Fig. 14). Birremes, laminares; artículo basal curto, comparandose aos ramos do apêndice, com uma ou duas setas simples medianas; ramos internos, ou endopoditos, sub-retangulares, bordo distal arredondado, com 18 a 19 setas setulosas marginais e três setas simples sub-marginais; ramos externos, ou exopoditos, sub-retangulares, com bordo distal arredondado, com 20 a 23 setas setulosas marginais e três setas simples sub-marginais; setas setulosas do endopodito e do exopodito dos urópodos ultrapassando o comprimento dos próprios ramos.

\section{DISCUSSÃO}

A eclosão de uma forma semelhante ao adulto, caracterizada como juvenil (sensu WILLIAMSON 1969), com desenvolvimento epimórfico, onde a formação dos segmentos e apêndices ocorrem dentro do ovo, revela uma adaptação da espécie ao ambiente de água doce impedindo que sejam arrastadas pela correnteza (KAESTNER 1980). Neste contexto, as espécies de Aeglidae, particularmente A. prado, mostram uma adaptação ao ambiente límnico. MAGALHÃES \& WALKER (1988) estudando camarões da região amazônica, relacionaram características do ciclo de vida de alguns Palaemonidae a fatores ecológicos, atribuindo às espécies com estágios larvais livre-natantes o desenvolvimento relacionado a corpos de água estacionários ou de baixa correnteza, com recursos minerais e iluminação suficientes para manter o fito e o zooplâncton. Por outro lado, as espécies com desenvolvimento direto e hábitos bentônicos, colonizariam corpos de água com pouca iluminação, muita correnteza e pobres em recursos minerais, como é o caso de $A$. prado encontrada no banhado do Taim, caracterizado como ambiente oligotrófico.

Nos exemplares de juvenis de $A$. prado examinados não foram observados os pleópodos, o que corrobora as observações de RAVINDRA et al. (1993) em porcelanídeos, onde o aparecimento dos apêndices sexuais ocorre a partir do segundo ínstar juvenil para machos e do quarto ínstar para fêmeas, sendo, portanto, inexistentes no primeiro estágio pós-embrionário.

Os estetascos (Fig. 15), setas especializadas na quimiorrecepção, do tipo papiliformes encontrados nas antênulas de $A$. prado enquadram-se na decrição de SHENOY et al. (1993) descritas para camarões e caranguejos de água doce. 


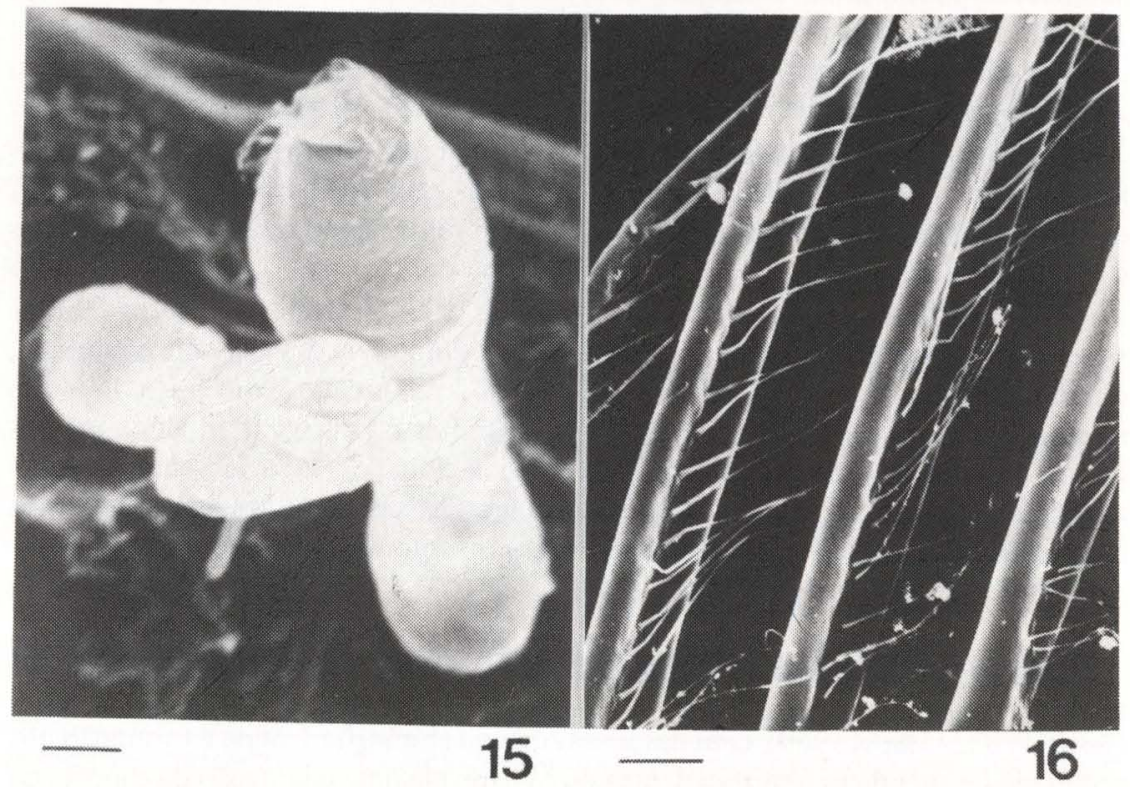

Figs 15-16. Aegla prado, primeiro estágio juvenil. (15) Estetascos da antênula em vista apical; (16) setas setulosas do telso. Escala $=10 \mu \mathrm{m}$.

Em relação as peças bucais, estas apresentam-se com estrutura semelhante a do adulto. A presença das mandíbulas, com seus dentes e dentículos robustos e palpo mandibular constituem um forte indício da fase juvenil. Além das mandíbulas, a morfologia das demais peças bucais, como as maxilas e os maxilípodos, corroboram a caracterização desse estágio. O escafognatito da maxila do juvenil de $A$. prado assemelha-se mais com a sequência do desenvolvimento do tipo B da pós-larva, descritas por VAN DOVER et al. (1982). Este tipo de sequência de desenvolvimento do escafognatito é característico das famílias Porcellanidae e Galatheidae, sendo caracterizada pela expansão do lobo anterior, resultando um escafognatito com lobos anteriores e posteriores com setação marginal. Entretanto, não se pode afirmar se esta sequência de desenvolvimento do escafognatito ocorre em toda a família Aeglidae, por não se conhecer o desenvolvimento pós-embrionário das demais espécies.

O telso apresenta-se com forma própria, sem sutura longitudinal, enquanto que no adulto, da espécie em questão, o telso é bipartido. 

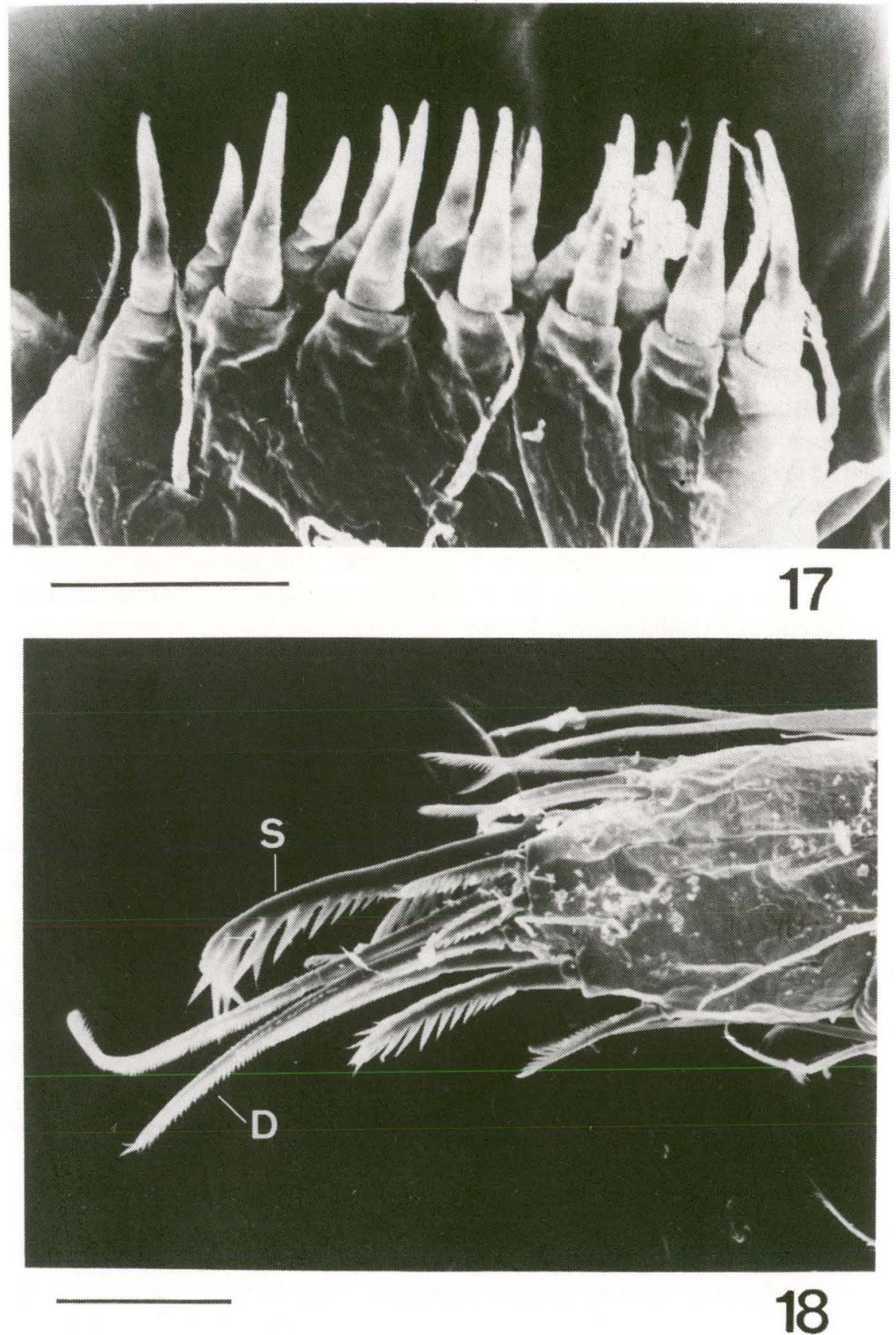

Figs 17-18. Aegla prado, primeiro estágio juvenil. (17) Setas cuspidadas da maxílula; (18) setas denticuladas (D) e serradas (S) do terceiro maxilipodo. Escala $=50 \mu \mathrm{m}$. 
AGRADECIMENTOS. Agradecemos o apoio recebido do Conselho Nacional de Desenvolvimento Científico e Tecnológico ( $\mathrm{CNPq})$, da Fundação de Amparo à Pesquisa do Rio Grande do Sul (FAPERGS) e da Pró-Reitoria do Ensino e da Pesquisa da Universidade Federal do Rio Grande do Sul (PROPESP/UFRGS) na realização deste projeto. Especial agradecimento aos Drs. D. Calazans e L. Buckup, pelas preciosas sugestões ao manuscrito; à bióloga Ana Rossi pelo auxílio na confecção dos desenhos.

\section{REFERÊNCIAS BIBLIOGRÁFICAS}

Bersano, J.G.F. \& G.A. BoxshalL. 1994. Planktonic of the genus Oncaea Phillipi (Poecilostomatoida: Oncaeidae) from the waters off southern Brazil. Nauplius, Rio Grande, 2: 29-41.

Bond-BuCKuP, G. \& L. BuCKUP. 1994. A família Aeglidae (Crustacea, Decapoda, Anomura). Arq. Zool., São Paulo, 32 (4): 159-347.

Calazans, D. 1992. Taxonomy, distribution and abundance of protozoea, mysis and megalopa stages of penaeidean decapod from the southern Brazilian coast. Thesis, unpublished, University of London, London, 435p.

FELDER, L.D.; W.J. MARTIN \& W.J. GoY. 1985. Patterns in early postlarval development of decapods, p.163-225. In: A.M. WENNER (Ed.). Larval Growth. Boston, A.A. Balkema, vol. 2, 236p.

GORE, R.H. 1985. Molting and growth in decapod larvae, p.1-65.In: A.M. WENNER (Ed.). Larval Growth. Boston, A.A. Balkema, vol. 2, 236p.

Kaestner, A. 1980. III Crustacea, vol. 3. In: R.E. KRIEGER (Ed.). Invertebrate Zoology. Huntington, VII+52p.

MAGALHÃES, C. \& I. WALKER, I. 1988. Larval development and ecological distribution of Central Amazoniam Palaemonid shrimps (Decapoda, Caridea). Crustaceana 55 (3): 279-292.

Negreiros-Fransozo, M.L. 1986 Desenvolvimento pós-embrionário de Eurypanopeus abbreviatus (Stimpson, 1860) (Crustacea, Decapoda, Xanthidae), em laboratório. Bolm Zool., São Paulo, 10: 19-39.

RAVINDRA, P.; K.N. SANKolli \& S. SHENOY. 1993 Juvenile morphology and appearance of sexual appendages in two Porcellanid crabs, Petrolisthes rufescens (Heller, 1861) and Psidia gordoni (Johnson, 1970) (Decapoda, Anomura, Porcellanidae). Crustaceana, 65 (3): 346-357.

Rodrigues, W. \& N.J. Hebling. 1978. Estudos Biológicos em Aegla perobae Hebling \& Rodrigues, 1977 (Decapoda, Anomura). Rev. Brasil. Biol. 38 (2): 383-390.

ScotTo, L.E. 1980. Studies on Decapod Crustacea from the Indian River Region of Florida. XIV: A Method for rapid preparation of Brachyuran larval for scanning electron microscopy. Crustaceana 38 (1): 99-101.

Shenoy, S.; D.R. Jalihal \& K.N. SANKolLI. 1993. Ecological diversity with references to aesthetascs in freshwater prawns. Crustaceana 65 (3): 300-308.

THOMAs, W.J. 1970. The setae of Austropotamolius pallipes (Crustacea: Astacidae). Jour. Zool., Londres, 160: 91-142. 
VAN DOVER, C.L.; J.R. FACTOR \& R.H. GoRE. 1982 Developmental patterns of larval scaphognatites: an aid to the classification of Anomuran and Brachyuran Crustacea. Jour. Crust. Biol. 2 (1): 48-53.

WATLING, L. 1989. A classification system for crustacean setae based on the homogy concept. In: B.E. FelgenhaUer; L. WATLING \& A.B. Thistle (Ed.). Functional Morphology of Feeding and Grooming in Crustacea. Boston, A.A. Balkema, Vol. 6, 240p.

Williamson, D.I. 1969. Names of larvae in Decapoda and Euphasiacea. Crustaceana 16 (2): 210-213.

Recebido em 30.X.1996; aceito em 27.XII.1996. 